\title{
Novel metal mesh filter using water-based regeneration for small-scale biomass boilers
}

\author{
Björn Baumgarten ${ }^{1}$ (1) Peter Grammer ${ }^{1}$. Ferdinand Ehard ${ }^{2} \cdot$ Oskar Winkel $^{3} \cdot$ Ulrich Vogt $^{4} \cdot$ Günter Baumbach $^{4}$. \\ Günter Scheffknecht ${ }^{4} \cdot$ Harald Thorwarth $^{1}$ (B)
}

Received: 15 April 2020 / Revised: 11 August 2020 / Accepted: 13 August 2020 / Published online: 29 August 2020

(C) The Author(s) 2020

\begin{abstract}
Particulate matter emissions are a key issue of modern biomass boilers. A novel gas cleaning method using a metal mesh filter combined with water-based cleaning was developed and tested. The filter was tested batch-wise. Flue gas of a commercial 50-kW boiler was filtered until a pressure drop of $2000 \mathrm{~Pa}$ was reached. Afterwards, the filter was regenerated. The initial prototype used ultrasound in order to remove the filter cake from the filter candles. Regeneration was complete and, even after boiler malfunctions producing tar, the filter cake could still be removed. Given the good results, a second cleaning mode, flushing the filter candles with water, was tested. The results were as good as with ultrasonic cleaning. Peak mass collection efficiency was very high with $98 \pm 2 \%$ (burning wood pellets). However, directly after cleaning, the first layer of filter cake has to be developed. In this initial phase, collection efficiency is low. Service time until maximum pressure drop was reached depended on the gas velocity. Using pellets as fuel, at a gas velocity of $66.6 \mathrm{~m} / \mathrm{h}, 12-\mathrm{h}$ service time was reached and $4.1 \mathrm{~g}$ dust was collected per square meter filter surface, while at $33.3 \mathrm{~m} / \mathrm{h}$, service time increased to $55 \mathrm{~h}$ and collected dust to $13.9 \mathrm{~g} / \mathrm{m}^{2}$. Using low-quality wood chips, the raw gas dust loading was much higher but also the maximum loading of the filter was higher with 13.3 to $28.9 \mathrm{~g}$ dust separated per square meter. Still, the service time decreased to 3.4 respective $38 \mathrm{~h}$. Peak collection efficiency increased to $99.5 \pm$ $0.8 \%$. The overall collection efficiency including the buildup of the filter cake depends on the gas velocity and fuel. It ranges from $74 \pm 4$ to $91 \pm 1 \%$. The feasibility of the filter concept could be proven, and further development towards a commercial application is in progress. Metal mesh filters with countercurrent cleaning showed a high potential given their simple and robust design, as well as high collection efficiency.
\end{abstract}

Keywords Biomass combustion · Particulate matter $\cdot$ Particulate matter filter $\cdot$ Ultrasound cleaning $\cdot$ Emission control $\cdot$ Baghouse filter - Ultrafine dust

Electronic supplementary material The online version of this article (https://doi.org/10.1007/s13399-020-00959-9) contains supplementary material, which is available to authorized users.

Björn Baumgarten

baumgarten@hs-rottenburg.de

1 University of Applied Sciences Rottenburg, Schadenweilerhof, 72 108 Rottenburg am Neckar, Germany

2 LK Metallwaren GmbH, Am Falbenholzweg 36, 91126 Schwabach, Germany

3 Oskar Winkel Filtertechnik, Kaiser-Wilhelm-Ring 30, 92224 Amberg, Germany

4 University of Stuttgart, Pfaffenwaldring 23, 70569 Stuttgart, Germany

\section{Introduction}

Combustion of biomass, in particular wood, is a traditional way of heating, which is gaining new importance given the climate change and that the world strives to reduce $\mathrm{CO}_{2}$ emissions. However, during the combustion of biomass, a variety of pollutants are emitted. In order to be a viable alternative to other heat sources, emissions have to be restricted. Modern boilers already implement a variety of primary measures to minimize emissions [1]. These are able to reduce gaseous emissions like $\mathrm{CO}$ and $\mathrm{NO}_{x}$ to a minimum and ensure good burnout and thus efficiency of boilers. However, in addition to gases, particulate emissions occur. Particulate matter is linked to respiratory diseases, cardiovascular effects, and cancer [2, $3]$. Especially very small particles ( $<\mathrm{PM1})$, with a high content of polycyclic aromatic hydrocarbons, are proven to cause 
cytotoxic and genotoxic responses [4]. In legislation, demanding limits of fine particle emissions are established. In Germany, the limit for household furnaces is $0.02 \mathrm{~g} / \mathrm{m}^{3}$ dust $\left(\mathrm{STP}, 13 \% \mathrm{O}_{2}\right)$ [5]. In order to meet these, primary measures are not sufficient and cannot guarantee compliance with the legal limits under realistic operation conditions [6]. Especially modulating load and lower fuel quality cause violations of the limits. Starts and stops contribute considerably to total emissions but are not taken into consideration in legislation [7].

Dust from biomass plants mostly consist of salts of potassium, sodium or zinc, and chloride or sulfate. These are referred to as aerosol forming elements. Even though the release mechanisms are quite complex [8-12], there is a strong correlation between the content of aerosol forming elements and dust emissions [13-16]. As such, there were various attempts to limit the dust generation by binding of the aerosol forming elements, either by addition of additives like kaolin, which should bind primarily potassium in the grate ash [17-22], or alternatively by fire bed cooling to avoid evaporation [23]. Addition of kaolin proved to be effective; however, it requires additional processing of fuel and increases the ash content of the fuels, which implies additional costs for fuel and disposal of ashes. If the emission limit shall be reached without using additives and using common furnaces, a critical potassium content of about $500-600 \mathrm{mg} / \mathrm{kg}$ (dry basis) is assumed [24].

If low quality, cheap fuel with high potassium content is supposed to be burned; cleaning of flue gas is necessary in order to meet legislatory limits under realistic conditions.

In general, there are three main technologies in use to reduce the particle load of flue gas.

1. Cyclones are used to reduce coarse particle load in a variety of boilers; however, they are only effective for particles larger than $10 \mu \mathrm{m}$ [25].

2. Electrostatic precipitators (ESP) are used in large-scale power plants. Currently, they are getting introduced to the small-scale market, and first models are available. Commercial ESPs for small furnaces can remove up to $80 \%$ of the particles [26]. The collection efficiency of ESPs depends on particle size. Most effective is removal of particles bigger than $3 \mu \mathrm{m}$ and between $50 \mathrm{~nm}$ and 0.1 $\mu \mathrm{m}$. Between 0.03 and $0.2 \mu \mathrm{m}$, a local minimum exists due to a change of the charging mechanism. Particles smaller than $50 \mathrm{~nm}$ pass ESPs nearly entirely [27-29]. Thus, the legally requested limits are met, but the most dangerous particles remain in the exhaust gas.

3. Fabric filters are used in large-scale plants and have proven their capability to effectively collect all particles, including the finest particles smaller than $50 \mathrm{~nm}$ [1]. However, they exhibit a higher pressure drop, thus requiring additional ventilation and power. In addition, fabric filters are traditionally made of textile fabric, which is inflammable. Fabric filters need to be cleaned periodically, as pressure drop increases over time. This requires a periodic regeneration, which is usually realized using jet pulses [1]. Jet pulse use a short pulse of pressurized air, which creates a backflow in the filter as well as a mechanical movement, which removes the filter cake [30].

For small biomass plants (up to $1 \mathrm{MW}$ ), the standard procedure of using textile fabric and jet pulse was not commercially realized so far. While inflammable textile fabric filters are state of the art in large combustion plants, they cannot be used in small biomass combustion plants due to the danger of flying sparks in flue gas without the use of a cyclone [1]. As alternative, filters made of stainless-steel mesh was suggested to be used instead, but jet-pulse cleaning of these is problematic. As example, Hartmann et al. [31] used a fabric filter made of stainless-steel mesh with a jet-pulse cleaning facility for a grain combustion furnace. Collection efficiency was excellent with $95-99 \%$, but the pulses cleaned only parts of the filter while the filter cake remained present on the rest of the surface.

Still, similar metal mesh filters with jet-pulse cleaning were available for furnaces with a thermal output of 100 to $740 \mathrm{~kW}$. While a number of filters is still in use, they are not produced anymore. In order to avoid condensation, the filter is electrically preheated before ignition of the furnace. Schwabl et al. [32] worked on an improvement for these. During their work, Schwabl et al. developed a formula for the dust concentration in the exhaust gas. It is only indirectly dependent on the raw gas content, instead, it depends on the maximum pressure drop, the frequency of cleaning, the pressure of the jet-pulse, and the gas velocity [32].

Schiller and Schmid [33] pre-coated a fabric filter with coarse particles. The particulate matter was filtered in the top layers of the pre-coat, while the lower layers of pre-coat facilitated cleaning by separating the potentially sticky particles from the textile. Also, due to the pre-coating, particle slip until a filter cake is built up was avoided. However, the applying and recycling of the pre-coat requires additional machinery and thereby costs.

Struschka and Goy [34] developed a filter based on a stainless-steel mesh and brushes to remove the filter cake mechanically. While jet-pulse cleaning is a technology that is relatively easy to adapt, it comes with drawbacks: It requires pressurized air, and the cleaning pulses are relatively loud. While this is unproblematic for larger furnaces, it is not acceptable for small plants installed in the basement of houses. The mechanical cleaning was meant to avoid these issues, but the cleaning was not sufficient. Based on his work, a new solution was developed, which integrates an ultrasonic bath to clean the metal mesh. Ultrasound is already in widespread use for cleaning applications [35]. The main mode of cleaning is the formation of jets directed at the surface of objects 
emerged in the ultrasonic bath, which effectively removes particles [36]. Further contributing to a good cleaning result is the solubility of the main ash compounds in waterchloride and sulfate salts of potassium, sodium, calcium, and zinc [37-39].

In the current work, a metal mesh filter with ultrasonicassisted water cleaning prototype was tested with regard to regeneration feasibility, pressure drop development, and viable air velocity in order to assess the viability of ultrasound assisted regeneration for a commercial application. For a successful introduction into the market, not only the collection efficiency but also economics have to be taken into consideration. As such, additional tests were carried out using only countercurrent flushing instead of ultrasound cleaning, removing the need for an expensive ultrasound transducer. Ultrasound facilitates the cleaning process by generating jets, which mechanically remove particles at the surface of the filter immersed in the ultrasonic bath; however, it also generates noise, which might impact adaption of the technology. As long as regeneration is efficient without the use of ultrasound, it is advisable not to use it.

\section{Methods and material}

\subsection{Fabric filter}

The fabric filter (mesh size $25 \mu \mathrm{m}$ ) consists of stainless steel. The steel fabric is supported by a mesh and welded to form filter candles. In the filter housing, 15 filter candles $\left(0.08 \mathrm{~m}^{2}\right.$ filter surface each) in two rings surround the ultrasound rod transducer (SONOPUSH MONO SPM1500/25-495 VA, Weber Ultrasonics). The combined filter area is $1.2 \mathrm{~m}^{2}$. For cleaning, the filter house can be filled with water, and ultrasonic cleaning can be performed. The construction is shown in
Figs. 1 and 2. To avoid condensation during operation, the filter house is heated using an $800-\mathrm{W}$ barrel heater (Freek, custom build).

\subsection{Pellet and ash analysis}

All samples were taken and prepared according to DIN EN 14778 [40] and 14780 [41]. Ash content was analyzed according to EN ISO 18122:2016 [42] by heating $1 \mathrm{~g}$ milled samples $(<0.25 \mathrm{~mm})$ in a furnace (AAF $11 /$ 18, Carbolite). Moisture content was analyzed according to EN ISO 18134-2:2017 [43] by drying $300 \mathrm{~g}$ pellets or wood chips for $24 \mathrm{~h}$ at $105{ }^{\circ} \mathrm{C}$.

The calorific value of the pellets and ash was determined according to EN ISO $18125: 2017$ by milling to $0.25 \mathrm{~mm}$, pressing a pellet of around $1 \mathrm{~g}$, and combustion in a calorimeter (C 6000, IKA).

The ash was also combusted using the calorimeter in order to analyze the chloride and sulfur content. A total of $100 \mathrm{mg}$ of ash was combusted with the aid of a combustion bag and $250 \mathrm{mg}$ paraffin oil.

The combustion water from calorimetry was diluted with bi-distilled water to $50 \mathrm{ml}$, and the content of chloride and sulfur was measured using an IC (883 Basic IC plus, Metrohm) as described in EN ISO 16994:2016-12 [44].

For ultimate analysis, $40 \mathrm{mg}$ milled fuel sample was wrapped into zinc foil, pressed into a tablet, and analyzed using a vario MACRO cube (Elementar). For ash, $20 \mathrm{mg}$ of ash and $60 \mathrm{mg}$ of $\mathrm{WO}_{3}$ (Elementar) and zinc foil were pressed into a tablet.

Further chemical analysis was performed using an ICPOES (Spectroblue FMX 26, Spectro) after microwave digestion using $\mathrm{HCl}, \mathrm{HNO}_{3}$, and $\mathrm{H}_{2} \mathrm{O}_{2}$ following a routine developed by Tejada et al. [38].
Fig. 1 Design of the filter with ultrasonic rod and 15 filter candles

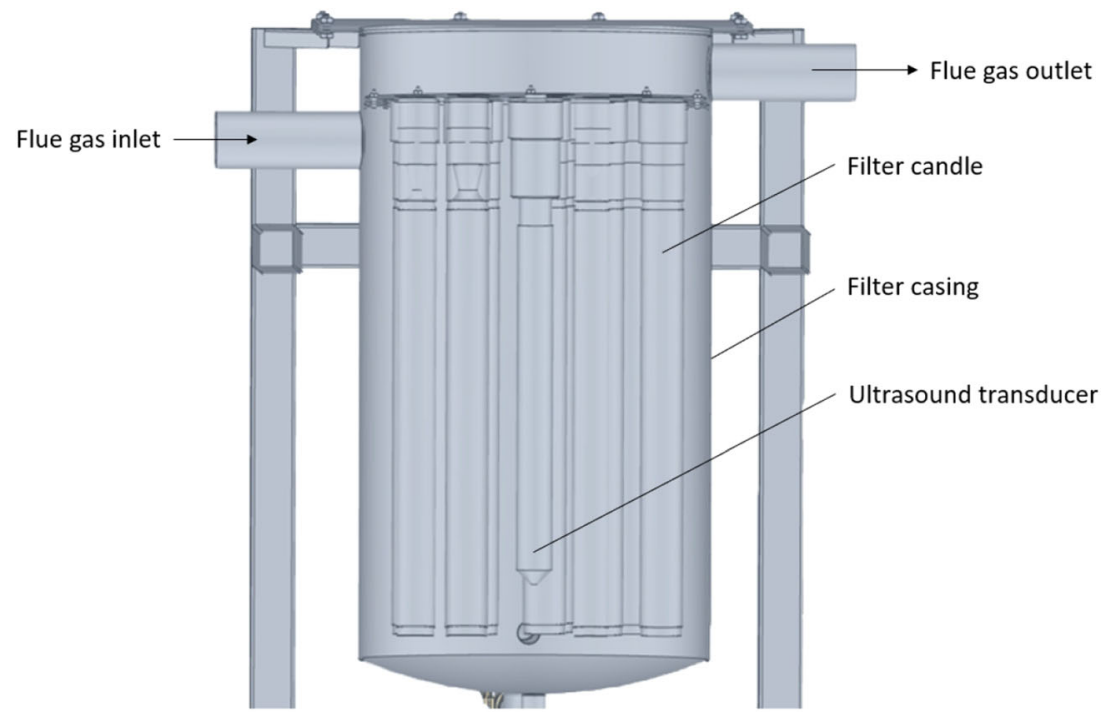


Fig. 2 Top view of the filter prototype

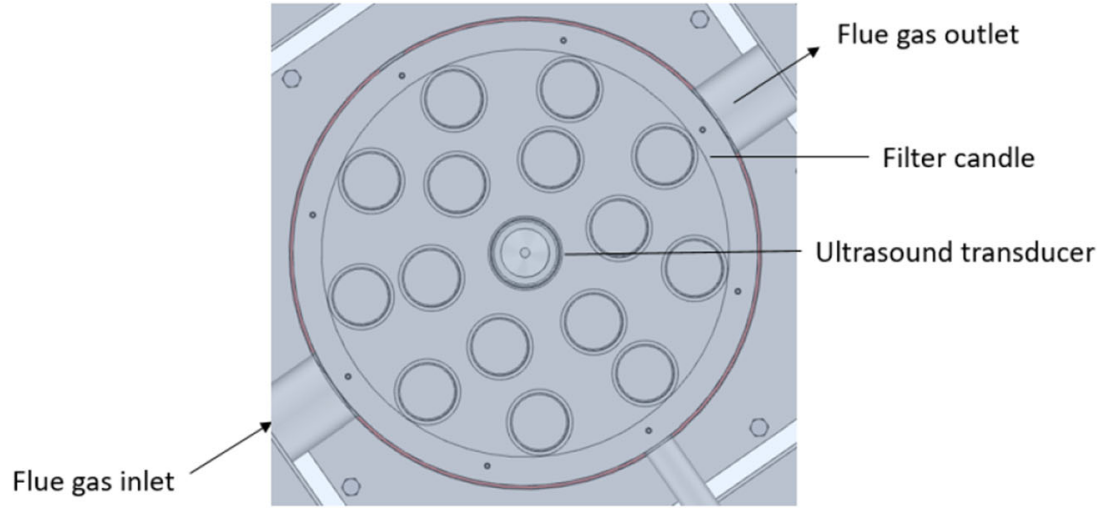

\subsection{Pellets and wood chips}

For the combustion tests, pellets were purchased from Scharr Wärme, while wood chips were purchased from Maschinenring Sulz GmbH. They were analyzed as described.

The results shown in Table 1 prove compliance with the relevant standards (EN plus A1 [45], DIN plus) and high quality of the pellets, with low amounts of aerosol-forming compounds (K, Na, Zn, S, Cl). Wood chips contain more aerosol-forming compounds.

\subsection{Operation test}

The filter was tested under standardized conditions. To achieve standardized conditions, an experimental setup was designed similar to DIN SPEC 33999 [46]. As emission source, a commercial moving grate boiler (KWB Multifire) was used. Its nominal thermal output is $50 \mathrm{~kW}$; however, for the experiments, it was set to $50 \%$ load. At this setting, around
$100 \mathrm{~m}^{3} / \mathrm{h}$ flue gas is produced with a nominal $\mathrm{O}_{2}$ concentration of $9.5 \%$. The design of the setup is depicted in Fig. 3.

In order to ensure normal operation of the boiler, a bypass allows free passage of the flue gas. Measurement data logging and process control was realized using Profimessage modules (2x ADIT) from Delphin. Using a side channel blower (Airtech ASC0080-1MT400-6) controlled via a software PID and a calorimetric flow meter (SEIKOM RLSW8AL), the filter was exposed to a defined volumetric flow between 40 and $80 \mathrm{~m}^{3} / \mathrm{h}$, equaling 33.3 to $66.6 \mathrm{~m} / \mathrm{h}$.

Temperature logging was performed upstream and downstream the filter using Type K thermocouples, a Pt100 integrated into the barrel heater, and a Pt100 installed close to the ultrasound generator inside the filter housing, which is used to control the barrel heater.

Gas analysis was performed with a modular tower from ABB Ltd. (CO, NO, $\mathrm{CO}_{2}, \mathrm{SO}_{2}$ : Uras 26, $\mathrm{O}_{2}$ : Magnos 206, VOC: Fidas 24).

PM measurement was conducted according to VDI-2066 [47] before and after the filter using plane quartz fiber filters

Table 1 Analysis of the fuels

\begin{tabular}{lllll}
\hline & & Pellets & Wood chips & Instrument \\
\hline Water content & & $6.54 \%$ & $15.96 \%$ & Drying oven \\
Ash content & d.b. & $0.3 \%$ & $2.11 \%$ & Ash oven \\
Lower heating value & d.b. & $18789 \pm 6 \mathrm{~J} / \mathrm{g}$ & $18327 \pm 5 \mathrm{~J} / \mathrm{g}$ & Calorimeter \\
$\mathrm{C}$ & d.b. & $500.8 \pm 4.3 \mathrm{~g} / \mathrm{kg}$ & $489.6 \pm 2.0 \mathrm{~g} / \mathrm{kg}$ & Elemental analyzer \\
$\mathrm{H}$ & d.b. & $65.2 \pm 0.6 \mathrm{~g} / \mathrm{kg}$ & $61.7 \pm 0.5 \mathrm{~g} / \mathrm{kg}$ & Elemental analyzer \\
$\mathrm{N}$ & d.b. & $0.8 \pm 0.1 \mathrm{~g} / \mathrm{kg}$ & $2.7 \pm 0.2 \mathrm{~g} / \mathrm{kg}$ & Elemental analyzer \\
$\mathrm{O}$ & d.b. & $432.6 \mathrm{~g} / \mathrm{kg}$ & $446.0 \mathrm{~g} / \mathrm{kg}$ & Calculated by difference \\
$\mathrm{Cl}$ & d.b. & $2.7 \pm 0.2 \mathrm{mg} / \mathrm{kg}$ & $5.9 \pm 0.3 \mathrm{mg} / \mathrm{kg}$ & IC \\
$\mathrm{S}$ & d.b. & $4.8 \pm 0.2 \mathrm{mg} / \mathrm{kg}$ & $17.7 \pm 4.3 \mathrm{mg} / \mathrm{kg}$ & IC \\
$\mathrm{Ca}$ & d.b. & $941 \pm 12 \mathrm{mg} / \mathrm{kg}$ & $7297 \pm 320 \mathrm{mg} / \mathrm{kg}$ & ICP-OES \\
$\mathrm{K}$ & d.b. & $537 \pm 7.8 \mathrm{mg} / \mathrm{kg}$ & $2247 \pm 76 \mathrm{mg} / \mathrm{kg}$ & ICP-OES \\
$\mathrm{Na}$ & d.b. & $3.3 \pm 1.7 \mathrm{mg} / \mathrm{kg}$ & $88.1 \pm 0.9 \mathrm{mg} / \mathrm{kg}$ & ICP-OES \\
$\mathrm{Zn}$ & d.b. & $13.6 \pm 1.9 \mathrm{mg} / \mathrm{kg}$ & $26 \pm 0.9 \mathrm{mg} / \mathrm{kg}$ & ICP-OES \\
\hline
\end{tabular}

d.b. concentrations on dry basis 


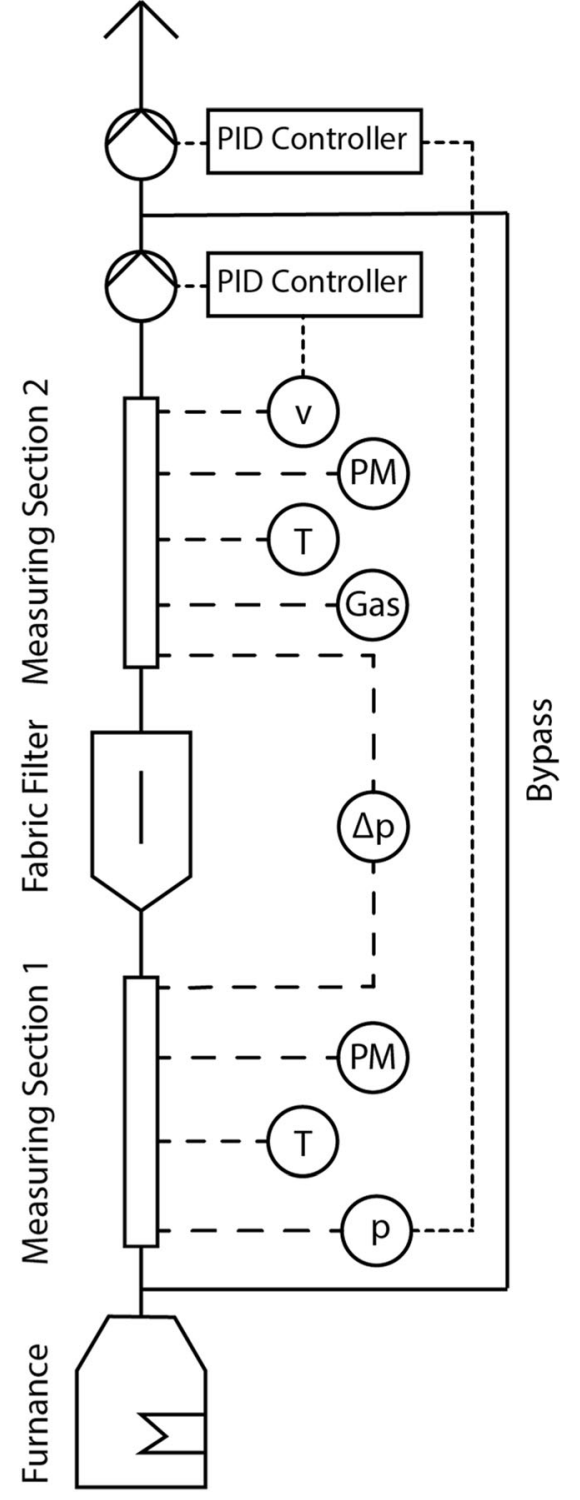

Fig. 3 Experimental set-up

(47-mm diameter, Munktell MG 160). For the raw gas, additional pre-filtration with plugged extra-fine glass wool (Karl Hecht $\mathrm{GmbH} \& \mathrm{CO} \mathrm{KG}$ ) was required if the measurement exceeded $1 \mathrm{~h}$. The PM filters and the glass wool were thermally treated at $200{ }^{\circ} \mathrm{C}$ before and $180{ }^{\circ} \mathrm{C}$ after measurement for $1 \mathrm{~h}$. After cooldown overnight using a desiccator, they were weighted in a climate-controlled room (Sartorius CPA $124 \mathrm{~S}$, readability $0.1 \mathrm{mg}$ ).

\subsection{Measurement procedure}

The filter house was preheated overnight. The boiler was started $2 \mathrm{~h}$ prior start of filtering in order to achieve steady state operation. Once filtering was started, PM sampling was performed as shown in Table 2 to account for the decreasing PM loading in the clean gas.
Once the pressure drop reached $2000 \mathrm{~Pa}$, the side channel blower was automatically shut down. Cleaning was performed by filling the filter house with water and applying ultrasound at $25 \mathrm{kHz}$ and $1500 \mathrm{~W}$ power for $15 \mathrm{~min}$. Alternatively, the filter candles were flushed with water by removing the top of the filter case and flushing the candles individually using a water hose.

In total, 7 test runs were carried out using ultrasonic cleaning as shown in Table 3: Three out of those with a gas velocity relative to the filter surface of $66.6 \mathrm{~m} / \mathrm{h}$, three with 50 $\mathrm{m} / \mathrm{h}$, and one with $33.3 \mathrm{~m} / \mathrm{h}$. During the run with $33.3 \mathrm{~m} / \mathrm{h}$, the boiler encountered an error and went into emergency shutdown. Tar deposits inside of the boiler from the shutdown changed the behavior of the boiler; thus, later runs are not directly comparable. It was attempted to perform a second run with $33.3 \mathrm{~m} / \mathrm{h}$; however, pressure drop increased more slowly. After a full week of operation, the pressure drop was still below $1300 \mathrm{~Pa}$. Given the different behavior and limited amount of pellets available, no further tests were performed.

For cleaning by flushing the filter with water, 9 test runs were conducted, 3 at each gas velocity. Due to technical issues, it was impossible to run the boiler without supervision as the wood chips had to be refilled every $30 \mathrm{~min}$. Thus, the maximum measurement time was $12 \mathrm{~h}$.

\section{Results}

Measurements of the gas concentrations were performed to measure the quality of combustion and to control gas leakage of the filter. The deviation between the lambda sensor of the furnace and the measured oxygen content was below $1 \%$ and within $1.5 \%$ of the nominal oxygen content of the furnace (9.5\%). In Fig. 4, gas concentrations of dust, $\mathrm{CO}, \mathrm{NO}_{x}$, and VOC emissions of the furnace are displayed. In general, emissions from pellet combustion were much lower compared with emissions from wood chip combustion. The average dust concentrations were very low, with about $7 \mathrm{mg} / \mathrm{m}^{3}$ (corrected to $13 \% \mathrm{O}_{2}$, STP) during pellet combustion and $49 \mathrm{mg} / \mathrm{m}^{3}$ during wood chip combustion. CO was $53 \mathrm{mg} / \mathrm{m}^{3}$ for pellets but 1838 $\mathrm{mg} / \mathrm{m}^{3}$ for wood chips. VOC was mostly below the detection limit during pellet combustion but at $45 \mathrm{mg} / \mathrm{m}^{3}$ during wood chip combustion. Average $\mathrm{NO}_{x}$ concentrations were $68 \mathrm{mg} /$ $\mathrm{m}^{3}$ with pellets and $113 \mathrm{mg} / \mathrm{m}^{3}$ with wood chips.

Pressure drop and dust collection efficiency are displayed in Figs. 5, 6, and 7 for flow velocities of 66, 50, and $33 \mathrm{~m} / \mathrm{h}$. In general, the process consists of two phases: In the first phase, the pressure drop is very low and collection efficiency is small. In the second phase, the collection efficiency increases rapidly to over $95 \%$, while the pressure drop increases continuously until the filter is shut down at $2000 \mathrm{~Pa}$. The main difference between the different gas velocities is the time until the maximum pressure drop is reached, while the general 
Table 2 PM sampling scheme

\begin{tabular}{lll}
\hline & Sample time & Pause between samples \\
\hline 1st sample & $15 \mathrm{~min}$ & $10 \mathrm{~min}$ \\
2nd to 4th sample & $30 \mathrm{~min}$ & $10 \mathrm{~min}$ \\
5th sample & $1 \mathrm{~h}$ & $10 \mathrm{~min}$ \\
6th to 7th sample & $4 \mathrm{~h}$ & $10 \mathrm{~min}$ \\
Night & - & Pause overnight \\
Additional samples & $2 \times 4 \mathrm{~h}$, afterwards pause overnight & $10 \mathrm{~min} /$ overnight \\
\hline
\end{tabular}

behavior is identical. During the runs with $33 \mathrm{~m} / \mathrm{h}$ with wood chips, the maximum pressure drop of $2000 \mathrm{~Pa}$ was not reached within the maximum operation time possible with our setup. The time until a pressure drop could be detected depends both on fuel quality and on gas velocity.

The average duration of the two phases, the overall collection efficiency, and the maximum pressure drop are summarized for each gas velocity in Table 4 . The figures as well as the table show that the second phase is prolonged if the gas velocity is reduced; thus, overall collection efficiency increases from 75 to $84 \%$ in case of pellets and from 83 to $91 \%$ in case of wood chips. The dependence of the first phase on gas velocity is inconsistent. It increases during reduction from 66.6 to $50 \mathrm{~m} / \mathrm{h}$; however, the effect of further reduction is much smaller in case of pellets; in the case of wood chips, it is reverted; and the buildup phase is shorter at $33.3 \mathrm{~m} / \mathrm{h}$ then 50 $\mathrm{m} / \mathrm{h}$. It is important to note that the maximum pressure drop of $2000 \mathrm{~Pa}$ was not reached during the runs with $33.3 \mathrm{~m} / \mathrm{h}$ gas velocity, so the overall efficiency would be higher.

In all cases, the regeneration led to a complete removal of the filter cake. This is depicted in Fig. 8. The pressure drop was reduced to zero, and there was no trend to shorter operation times. The filter was never regenerated using other methods than the mentioned ultrasound cleaning or flushing with water.

Deposited fly ash samples from pellet as well as wood chip combustion were taken from the filter and were chemically analyzed. The results can be found in Table 5. Main constituents of both ashes are potassium salts, with concentrations of 47.8 wt- $\%$ (pellets) and 41.9 wt- $\%$ (wood chips). Chloride

Table 3 Experimental runs

\begin{tabular}{llll}
\hline Gas velocity $(\mathrm{m} / \mathrm{h})$ & Repetitions & Cleaning mode & Fuel \\
\hline 66.6 & 3 & Ultrasound & Pellets \\
50 & 3 & Ultrasound & Pellets \\
33.3 & 1 & Ultrasound & Pellets \\
66.6 & 3 & Countercurrent flushing & Wood chips \\
50 & 3 & Countercurrent flushing & Wood chips \\
33 & 3 & Countercurrent flushing & Wood chips \\
\hline
\end{tabular}

concentrations amount to $14.7 \mathrm{wt}-\%$ and $25.8 \mathrm{wt}-\%$ and sulfur to 4.8 and 4.9 wt- $\%$. Wood chip ash contains much less chloride but approximately the same amount of sulfur as pellet ash. The carbon content is relatively low with 19.0 and $2.3 \mathrm{wt}-\%$. Another important constituent is zinc with $3.2 \mathrm{wt}-\%$ and 3.7 wt- $\%$. The calcium content is also low with concentrations of 1.5 and 0.4 wt- $\%$.

\section{Discussion}

Gas analysis was done primarily to monitor the tightness of the setup, especially at high pressure drops. The deviation between measured $\mathrm{O}_{2}$ concentration and nominal $\mathrm{O}_{2}$ concentration is within measurement error of the probes; thus, dilution effects by false air are negligible.

Additionally, $\mathrm{CO}, \mathrm{VOC}$, and $\mathrm{NO}_{x}$ emissions were monitored. $\mathrm{CO}$ and VOC can be used to control combustion quality; given the very low emissions observed with pellets (in case of VOC below detection limit), complete combustion can be assumed. CO and VOC emissions were significantly higher during wood chip combustion, indicating incomplete combustion. Still, CO emissions were well within German legal limits (average: $0.18 \mathrm{~g} / \mathrm{m}^{3}$, the limit is $0.4 \mathrm{~g} / \mathrm{m}^{3}$ ). In order to assess the regeneration of the filter under suboptimal conditions, wood chips of low quality (forest residue) were used. They do not fulfil all requirements of the boiler manufacturer; most notably, they were sieved to $32 \mathrm{~mm}$ maximum size instead of $16 \mathrm{~mm}$ maximum size. Given the wood chips are from forest residue, they are rich in bark and therefore aerosol forming elements as shown by the chemical analysis, resulting in the observed higher emissions.

Temperature measurements showed low gas temperatures in the range of $80^{\circ} \mathrm{C}$. Normally, at this low temperature, there is a risk of tar condensation. However, given no or only small concentrations of VOC were detected during normal boiler operation, no noticeable tar condensation should occur.

Measurement of the dust concentrations in the filtered gas was difficult. The boiler already emits very low amounts of around $7 \mathrm{mg} / \mathrm{m}^{3}$ using pellets. This can be accounted to the low amounts of potassium and other aerosol forming elements in the pellets. As a result, the plane filters used during 

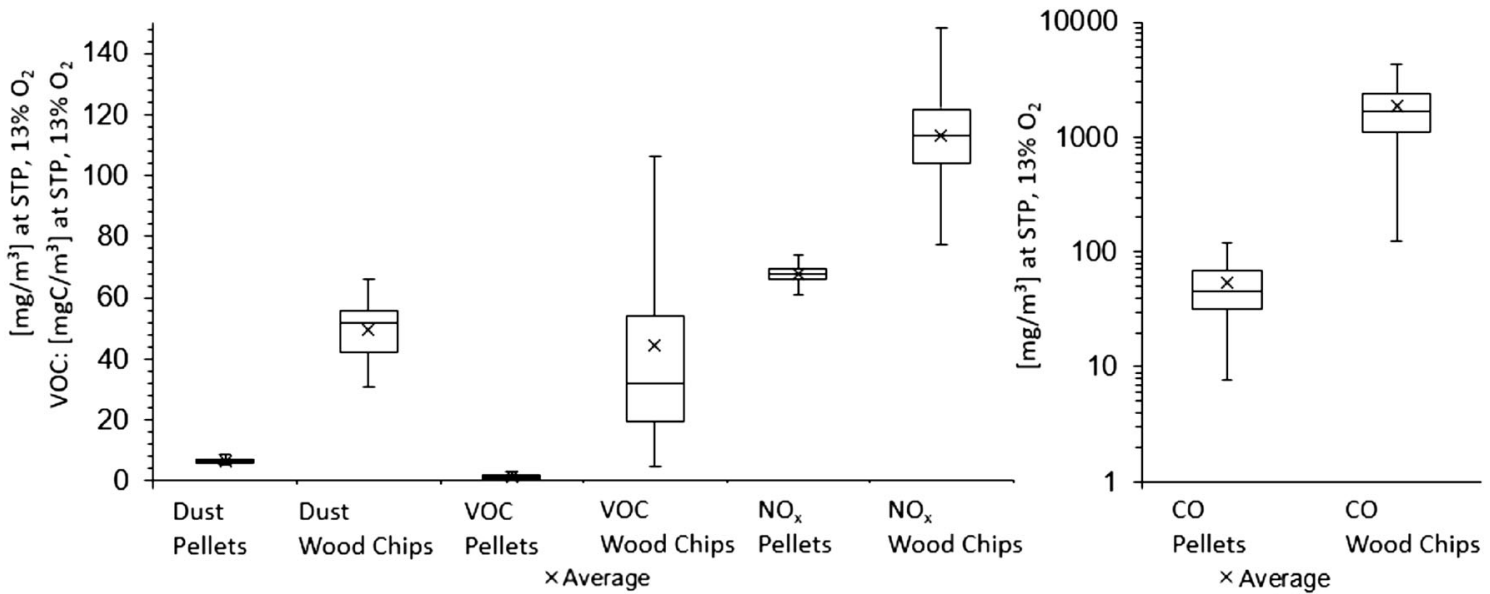

Fig. 4 Gas emissions of the KWB Multifire during operation with pellets and wood chips at $50 \%$ load (factory settings) over the course of an entire test run

gravimetric measurement of the dust concentration in the filtered gas were loaded with less than a microgram of dust, leading to a high standard deviation.

With wood chips, the boiler emits $49 \mathrm{mg} / \mathrm{m}^{3}$ at standard conditions $\left(13 \% \mathrm{O}_{2}\right)$, which is caused by the much higher amount of aerosol forming elements.

Two different phases can be identified in the pressure drop curves: During the first phase, the filter cake is accumulating, the collection efficiency is low, and a pressure drop cannot be measured. The collection efficiency during the first phase seems to decrease in the first minutes. This effect is most likely caused by condensation. During commissioning of the prototype, it was tested without preheating. There, the observed effect was much stronger. Even if it increases apparent collection efficiency, the collection efficiency of a metal mesh filter should be examined and not the effect of condensation on dust emissions. Thus, a barrel heater was purchased and installed. From an engineering point of view, it is not necessary and should not be added to a commercial version since it adds additional costs.

Once the filter cake is established, the second phase begins and the collection efficiency increases up to values close to
$100 \%$. While the pressure drop continuously increases, it follows an exponential slope.

The filter captured over $95 \%$ of the particulate emissions in the second phase. Given the low clean gas dust concentrations, the measured weight difference of the dust samples was below $1 \mathrm{mg}$ after $4 \mathrm{~h}$. The readability of the scale is 0.1 $\mathrm{mg}$. As a result, the measurement of the peak separation efficiency of pellets is relatively inaccurate with $98 \pm 2 \%$. Since the raw gas concentrations during wood chip combustion are much higher, the separation efficiency could be calculated with more precision to $99.5 \pm 0.8 \%$. Due to the measurement uncertainty, in some cases, negative dust concentrations were measured in the cleaned gas.

Overall collection efficiency is lower than the separation efficiency during the second phase, as significant penetration of the filter occurs during buildup of the filter cake. With decreasing gas velocity, the share of the filtering phase increases drastically. As such, the overall collection efficiency increases with decreasing gas velocity. Unfortunately, it was not possible to run the setup long enough to reach $2000 \mathrm{~Pa}$ pressure drop during the runs with low gas velocity. Still, the overall collection efficiency reached $91 \%$ with wood chips
Fig. 5 Pressure drop and collection efficiency of the metal mesh filter. Average of 3 runs at $66 \mathrm{~m} / \mathrm{h}$ flow velocity. Error bars equal standard deviation

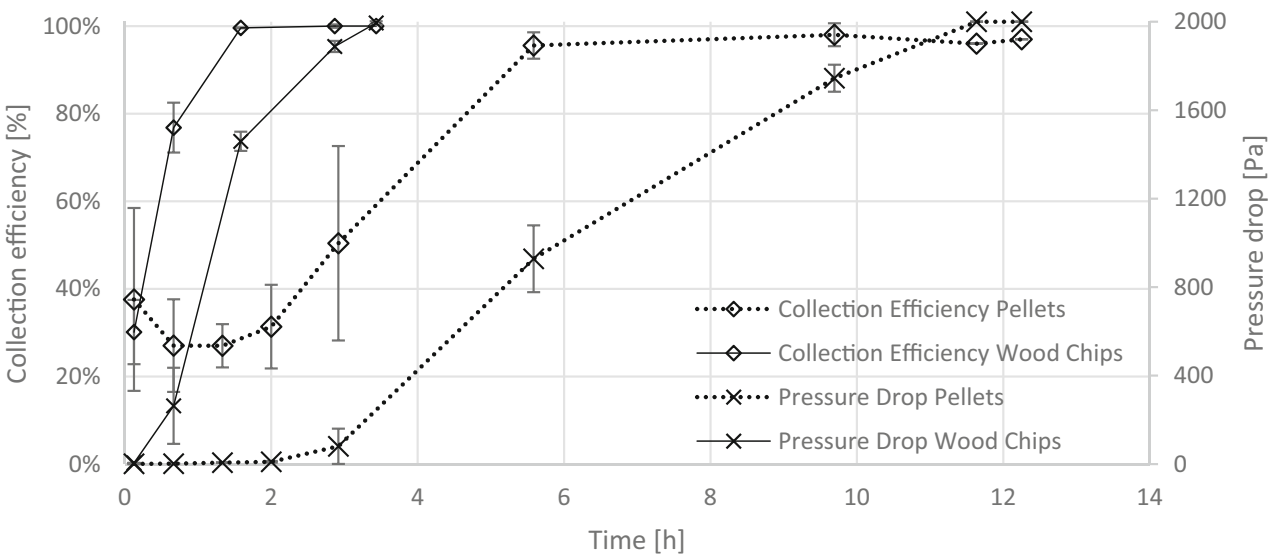




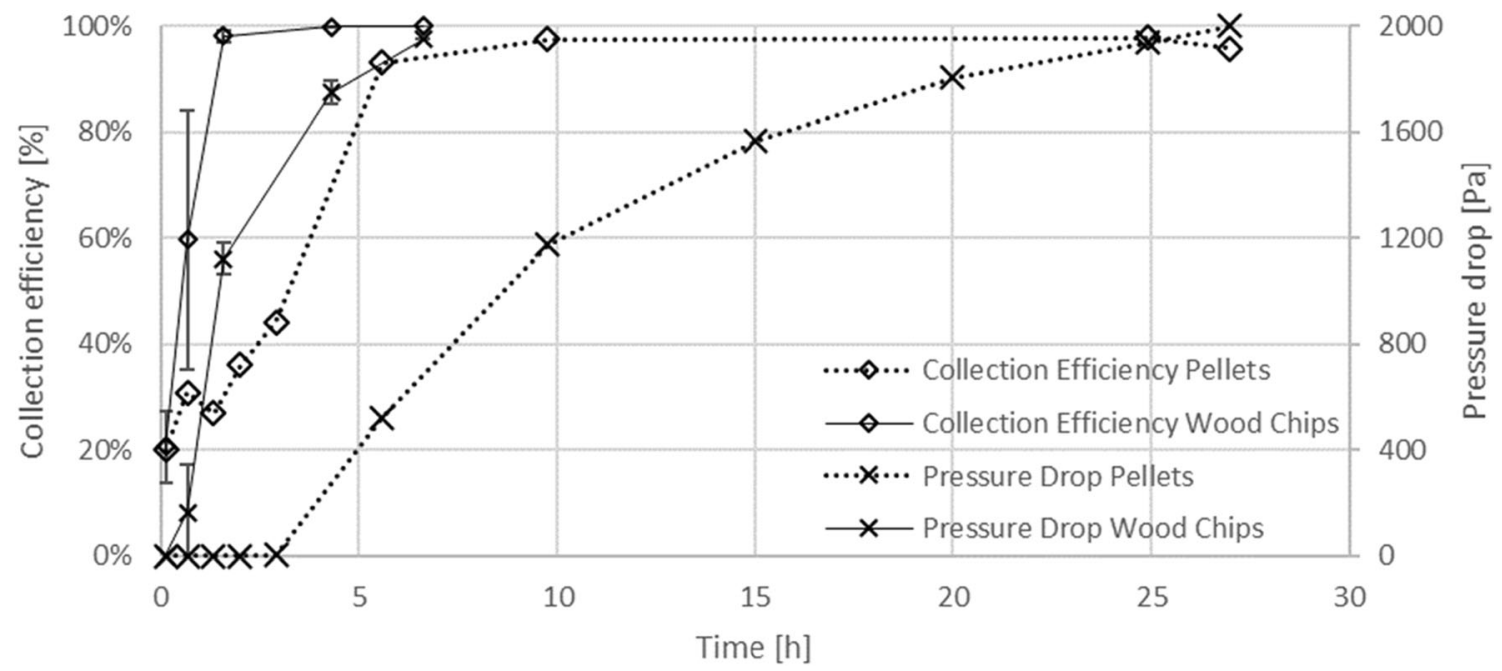

Fig. 6 Pressure drop and collection efficiency of the metal mesh filter. Average of 3 runs at $50 \mathrm{~m} / \mathrm{h}$. Error bars equal standard deviation

and $84 \%$ with pellets at the lowest gas velocity of $33.3 \mathrm{~m} / \mathrm{h}$. Pellet overall collection efficiency during the run with $50 \mathrm{~m} / \mathrm{h}$ was higher with $86 \%$ compared with the run at $33 \mathrm{~m} / \mathrm{h}$, but that is most likely due to the early stop of the test at $1585 \mathrm{~Pa}$ instead of $2000 \mathrm{~Pa}$.

The influence of the gas velocity on filter cake buildup is inconsistent. For pellets, the $24 \%$ decrease in gas velocity from 66.6 to $50 \mathrm{~m} / \mathrm{h}$ resulted in an increase of $72 \%$ in time until a filter cake was established, while the $33 \%$ decrease from 50 to $33.3 \mathrm{~m} / \mathrm{h}$ resulted only in an increase of $51 \%$.

For wood chips, the decrease from 66.6 to $50 \mathrm{~m} / \mathrm{h}$ led to a $28.8 \%$ increase of the duration of the first phase, while the decrease from 50 to $33.3 \mathrm{~m} / \mathrm{h}$ led to a decrease of $39.6 \%$. In fact, the buildup phase was shorter with a gas velocity of 33.3 $\mathrm{m} / \mathrm{h}$ then with $66.6 \mathrm{~m} / \mathrm{h}$. The exact reason for this behavior cannot be determined using the existing data. Potential causes might be electrostatic forces or diffusion playing a bigger role at lower velocities.
In order to compare the results of the different measurements, they were normalized. Given the pressure drop increases linearly with velocity, the pressure drop of all measurements was normalized to $50 \mathrm{~m} / \mathrm{h}$ using a linear approach (e.g., if the velocity was $60 \mathrm{~m} / \mathrm{h}$, the pressure drop was multiplied by 50/60). From the data of all runs excluding pressure drops below $500 \mathrm{~Pa}$, a model function of the form

$p=a D^{b}$

with $D$ being the collected dust per square meter and $a$ and $b$ being coefficients, was calculated for each fuel using the least square approach. In general, the pressure drop with wood chips was lower than with pellets. The coefficients were $a=$ 814.41 and $b=0.4544$ for pellets and $a=627.72$ and $b=$ 0.4125 for wood chips. The function and all measurements for comparison are displayed in Fig. 9. Based on that, it is possible to approximate the operation time in dependence of

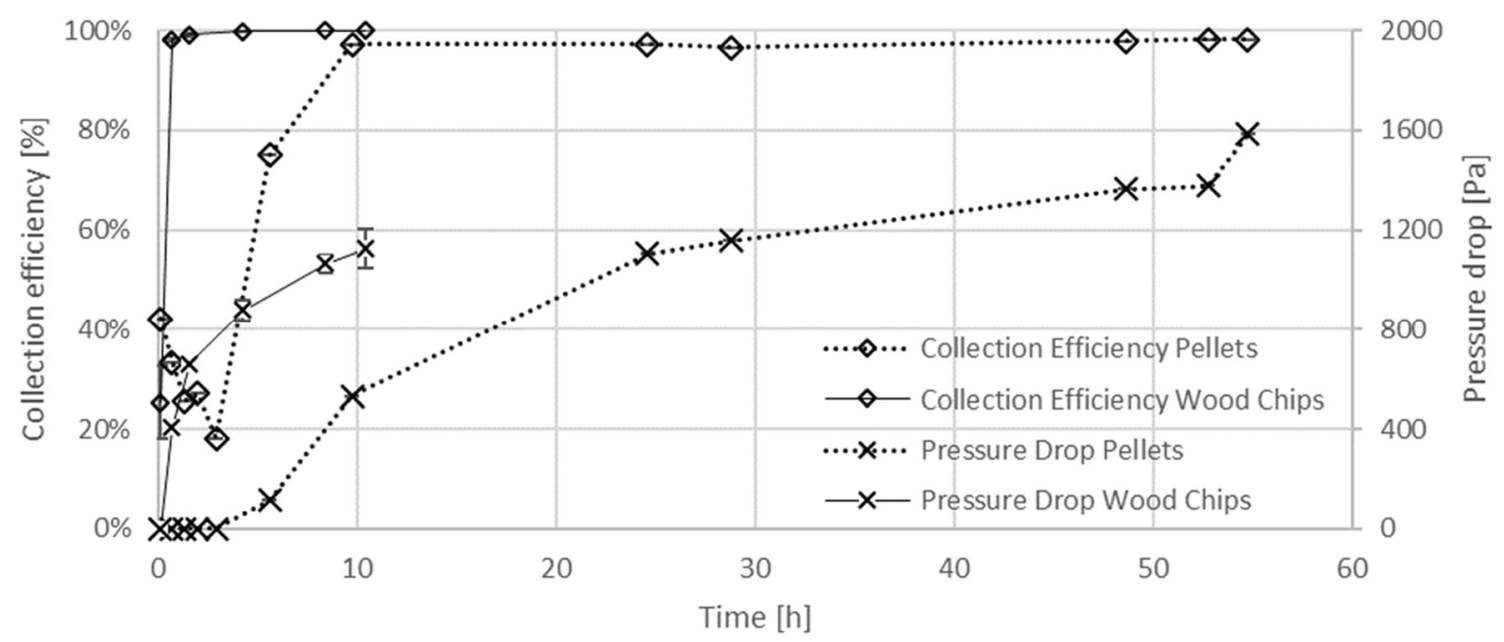

Fig. 7 Pressure drop and collection efficiency of the metal mesh filter. Single run at $33 \mathrm{~m} / \mathrm{h}$ for pellets and average of 3 runs for wood chips 
Table 4 Duration of the phases and overall collection efficiency

\begin{tabular}{lllll}
\hline & Phase 1 & Phase 2 & Overall collection efficiency & Maximum pressure drop \\
\hline $\mathrm{m} / \mathrm{h}$ & $(\mathrm{h})$ & $(\mathrm{h})$ & $(\%)$ & $(\mathrm{Pa})$ \\
Pellets & & & & \\
66.6 & $1.8 \pm 0.6$ & $9.9 \pm 0.5$ & $75 \pm 4$ & 2000 \\
50 & $3.1 \pm 0.5$ & $22.0 \pm 3.0$ & $86 \pm 1$ & 2000 \\
33.3 & 4.7 & 49.3 & 84 & 1585 \\
Wood chips & & & & 2000 \\
66.6 & $0.45 \pm 0.1$ & $3.0 \pm 0.1$ & $83 \pm 1$ & 2000 \\
50 & $0.58 \pm 0.15$ & $5.5 \pm 0.4$ & $86 \pm 3$ & $1190-1266$ \\
33.3 & $0.35 \pm 0.05$ & $10 \pm 0.1$ & $91 \pm 1$ &
\end{tabular}

the gas velocity and dust concentration in the flue gas by replacing $\mathrm{D}$ with $c_{\text {Dust }} * v$ and introducing a linear correction factor for the gas velocity $\mathrm{v} / 50 \mathrm{~m} / \mathrm{h}$ :

$t_{\max }=\frac{p_{\max }}{\left(a c_{\text {Dust }} \frac{v^{2}}{50 \frac{m}{h}}\right)^{b}}$

$t_{\max } \quad$ maximum operation time $(\mathrm{h})$

$p_{\text {max }}$ maximum pressure drop $(\mathrm{Pa})$

$a, b \quad$ coefficients from least square approximation

$v \quad$ gas velocity $(\mathrm{m} / \mathrm{h})$

$c_{\text {Dust }}$ dust concentration in the flue gas $\left(\mathrm{g} / \mathrm{m}^{3}\right)$

Using an average raw gas dust concentration of $7 \mathrm{mg} / \mathrm{m}^{3}$ for pellets and $49 \mathrm{mg} / \mathrm{m}^{3}$ for wood chips, the operation time until $2000 \mathrm{~Pa}$ pressure drop is reached is displayed in Fig. 10. Using the data, it is possible to determine the optimum filter surface. Depending on the cleaning mode (e.g., shutdown of the furnace and then cleaning or using multiple filters in

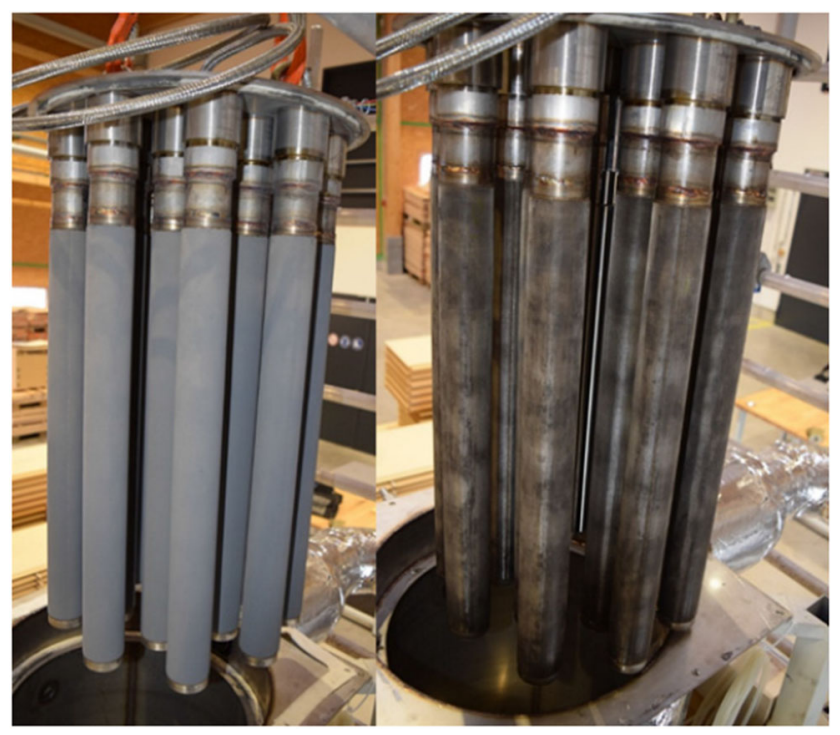

Fig. 8 Metal mesh filter before and after cleaning parallel, which are cleaned one after another enabling continuous operation), the required surface is different.

The composition of the particles is mostly as expected. Given the low concentration of $\mathrm{CO}$ and VOC in flue gases, the carbon content is low. While the relative content of carbon in the pellet ash is higher than in the wood chip ash, the absolute concentration in the flue gas is approximately 1.2 $\mathrm{mg} / \mathrm{m}^{3}$, while the concentration in the flue gas from wood chip combustion is approximately $1.1 \mathrm{mg} / \mathrm{m}^{3}$. This indicates that the generation of dust with compounds incorporating carbon is independent from the amount of aerosol-forming elements and approximately equal for both fuels even though the combustion quality of the wood chips is not as good. However, it is also important to note that not all of the carbon found in dust has to originate from incomplete combustion but can also occur as carbonates of the inorganic compounds like potassium.

In general, the volatile elements (potassium, zinc, sulfur, chloride, sodium) can be found in the fly ash as expected. The biggest constituent is potassium with 47.8 (pellets) and $41.9 \%$ (wood chips), followed by chlorine and sulfur.

A more detailed analysis can be found in the supporting information including all elements with a concentration of

Table 5 Fly ash composition

\begin{tabular}{llll}
\hline & Pellet ash (wt-\%) & Wood chip ash (wt-\%) & Instrument \\
\hline $\mathrm{C}$ & $18.97 \pm 1.40$ & $2.31 \pm 0.20$ & Elemental analyzer \\
$\mathrm{H}$ & $0.47 \pm 0.03$ & $0.36 \pm 0.01$ & Elemental analyzer \\
$\mathrm{N}$ & $0.22 \pm 0.05$ & $2.56 \pm 0.01$ & Elemental analyzer \\
$\mathrm{Cl}$ & $14.7 \pm 1.3$ & $25.8 \pm 2.9$ & $\mathrm{IC}$ \\
$\mathrm{S}$ & $4.8 \pm 1.2$ & $4.9 \pm 0.8$ & $\mathrm{IC}$ \\
$\mathrm{Ca}$ & $1.54 \pm 0.02$ & $0.41 \pm 0.01$ & $\mathrm{ICP}-\mathrm{OES}$ \\
$\mathrm{K}$ & $47.83 \pm 2.54$ & $41.95 \pm 0.79$ & ICP-OES \\
$\mathrm{Na}$ & $0.32 \pm 0.01$ & $0.67 \pm 0.02$ & ICP-OES \\
$\mathrm{Zn}$ & $3.24 \pm 0.11$ & $3.77 \pm 0.08$ & ICP-OES \\
\hline
\end{tabular}

Elemental concentrations on dry basis 


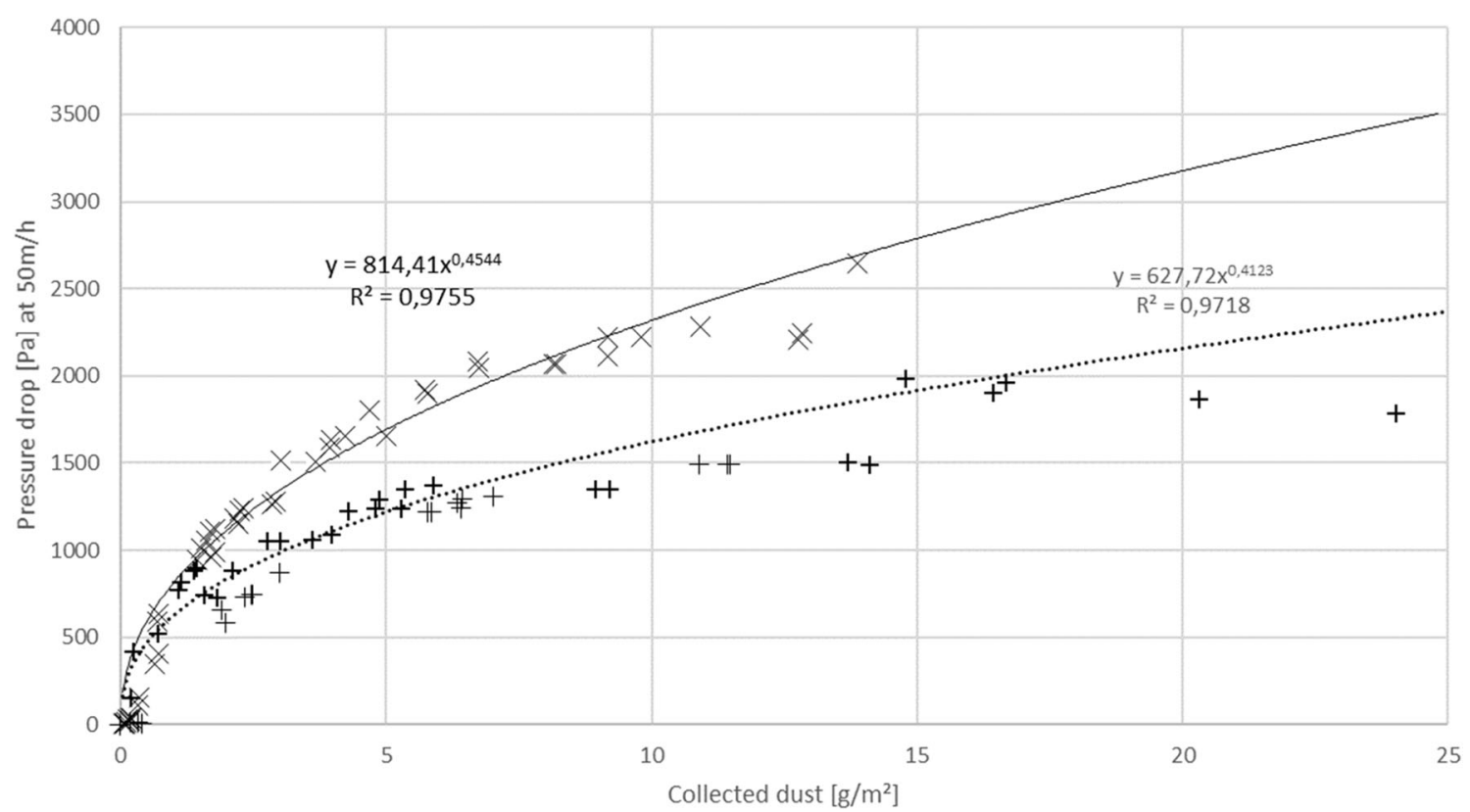

Fig. 9 Model functions of the pressure drop. Solid line: pellets, dotted line: wood chips. Each cross marks an individual measurement. For the regression curve, values below $500 \mathrm{~Pa}$ were ignored

more than $500 \mathrm{mg} / \mathrm{kg}$ (wood chips: more than $100 \mathrm{mg} / \mathrm{kg}$ ) in the fly ash.

Cleaning of the filter was expected to be the biggest issue of this work. Instead, the ultrasonic cleaning procedure was successful in all cases. Even after maloperations of the boiler, which caused tar formation, the standard cleaning procedure was sufficient and no additives were required. Given that regeneration by ultrasound cleaning was successful for the first batch of experiments, during the second set of experiments, with the more challenging fuel quality, the filters were only flushed with water and no ultrasound bath was used. It was impossible to detect any efficiency differences between the different cleaning modes, even though the cleaning mechanism of ultrasound and flushing with water are very different. In an ultrasonic bath, cavitation bubbles generate small jets of water directed to the surface and removing any particles as described by Chahine et al [36]. These occur in the entire bath, resulting in a uniform cleaning. At the used frequency, the ultrasound waves cannot penetrate the mesh; however, as the filter cake is on the outside of the candles, that is not necessary.

Cleaning using water is not uniform, as the water flows through the candle. Potentially, it is possible that only parts of the filter cake are removed and the water starts flowing

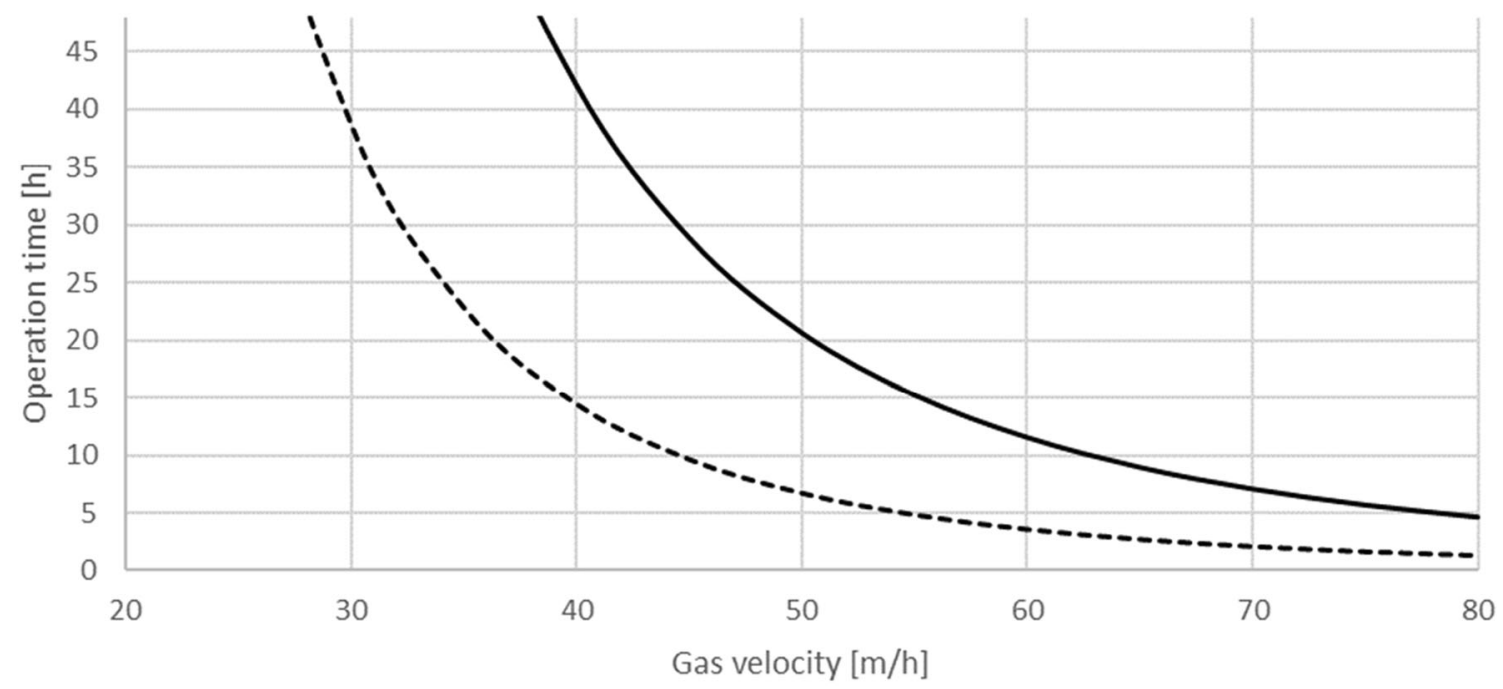

- Pellets ----Wood Chips

Fig. 10 Operation time until 2000 Pa pressure drop dependent on the gas velocity through the filter 
through the already cleaned part of the candle, while the rest of the filter cake remains.

Still, both cleaning modes achieved the same cleaning effect. No residual pressure drop could be recorded after regeneration of the filter. In the supplementary information, the results from the individual test runs in chronological order can be found. No negative trend of the operation time could be recorded during the repetitions at the same gas velocity. Optical inspection of the filter indicates complete removal of the filter cake in all cases. Since it was possible to remove the filter cake after tar generation, the filter can most likely be used during start and stop of the filter. Given that these are phases with very high emissions, that is a major advantage.

Compared with traditional jet-pulse cleaning, the behavior of the filter is different. As discussed by Dittler [30], Hartmann et al. [31], and Schiller and Schmid [33], jet-pulse cleaning results in a residual pressure drop after cleaning. For example, during the experiments of Schiller and Schmid, the residual pressure drop was about $400 \mathrm{~Pa}$. Also, Hartmann et al. reported a residual filter cake after cleaning. In contrast, cleaning using water removes the entire filter cake, resulting in no residual pressure drop. It is also to be noted that, after each cleaning pulse, a considerable amount of dust passes jet-pulse filters, similar to the first phase described here in which the filter cake has to build up. Schwabl et al. [32] state that the separation efficiency of a fabric filter cleaned by jet-pulse depend mostly on the maximum pressure drop, the pressure of the jet-pulse, gas velocity, and cleaning frequency. This is also true for water cleaning; similar to their findings, the separation efficiency increases with lower gas velocity and cleaning frequency, while it improves with a higher maximum pressure drop due to the prolonged phase of filtering.

Another major difference is the resistance against condensation of water or tar. The filter designs discussed by other researchers all require either preheating or a bypass in order to avoid condensation, as condensation would permanently block the filters. During the experiments reported in the present paper, the filter was also preheated in order to avoid the influence of condensation on separation efficiency but not for operational problems. In a commercial application, no preheating is necessary as the cleaning is based on water. Due to the additional mass, which has to be heated up during the start, condensation might occur for a longer time in the exhaust system. Thus, it is necessary to use an appropriate chimney that will not corrode.

\section{Conclusion}

As shown by the results, fabric filters offer a possibility to limit particulate matter emissions of biomass plants to an absolute minimum and a regeneration using water is feasible. In order to avoid flammability, the application of a metal mesh proved to be feasible. Collection efficiencies exceeding 95\% are reached once a filter cake is established. Regeneration using simple flushing is a viable, reliable solution and resulted in a reproducible cleaning without any signs of decay. Flushing of the filter is silent, enabling the use in small household furnaces. It was also possible to demonstrate a nonlinear relationship between gas velocity and time until regeneration of the filter is necessary.

During the buildup phase, penetration of the filter is significant. Thus, the buildup phase has to be limited. A possible option is to decrease the gas velocity and thereby exploiting the nonlinear relationship between gas velocity and pressure drop buildup.

Further research with different biomass is necessary in order to explore the potential of metal mesh filters under more realistic conditions including startups and modulating load. A 3-month test is planned for beginning of 2020 with a commercial prototype. The commercial prototype consists of two modules, thus enabling continuous gas cleaning while one module is regenerated. If very high separation efficiencies are required, another option would be to operate both filters in line directly after cleaning. This would negate the particle slip during build-up of the filter cake but requires additional effort. The commercial prototype is fully automated and, different compared with the current setup, can be used to determine costs. If cleaning without ultrasound proves to be viable over a long period of time, metal mesh filters might be a cost-efficient way to reduce particulate matter emissions to an absolute minimum including start and stop of furnaces. Also, it is required to assess whether an extensive treatment process of the water is required before it can be disposed into the municipal wastewater system.

Author contributions The manuscript was written through contributions of all authors. All authors have given approval to the final version of the manuscript.

Funding Open Access funding provided by Projekt DEAL. The Fachagentur Nachwachsende Rohstoffe (FNR), fund grant number 22019417, funds the project.

Open Access This article is licensed under a Creative Commons Attribution 4.0 International License, which permits use, sharing, adaptation, distribution and reproduction in any medium or format, as long as you give appropriate credit to the original author(s) and the source, provide a link to the Creative Commons licence, and indicate if changes were made. The images or other third party material in this article are included in the article's Creative Commons licence, unless indicated otherwise in a credit line to the material. If material is not included in the article's Creative Commons licence and your intended use is not permitted by statutory regulation or exceeds the permitted use, you will need to obtain permission directly from the copyright holder. To view a copy of this licence, visit http://creativecommons.org/licenses/by/4.0/. 


\section{References}

1. Gaderer M (2016) Abgasreinigung. In: Kaltschmitt M, Hartmann H, Hofbauer H (eds) Energie aus Biomasse, 3., aktualisierte Aufl. 2016. Springer Berlin Heidelberg; Imprint: Springer Vieweg, Berlin, Heidelberg, pp 936-972

2. Lewtas J (2007) Air pollution combustion emissions: characterization of causative agents and mechanisms associated with cancer, reproductive, and cardiovascular effects. Mutat Res 636(1-3):95133. https://doi.org/10.1016/j.mrrev.2007.08.003

3. Torres-Duque C, Maldonado D, Pérez-Padilla R et al (2008) Biomass fuels and respiratory diseases: a review of the evidence. Proc Am Thorac Soc 5(5):577-590. https://doi.org/10.1513/pats. 200707-100RP

4. Arif AT, Maschowski C, Garra P, Garcia-Käufer M, Petithory T, Trouvé G, Dieterlen A, Mersch-Sundermann V, Khanaqa P, Nazarenko I, Gminski R, Gieré R (1994) (2017) Cytotoxic and genotoxic responses of human lung cells to combustion smoke particles of Miscanthus straw, softwood and beech wood chips. Atmos Environ 163:138-154. https://doi.org/10.1016/j.atmosenv. 2017.05.019

5. (2019) Erste Verordnung zur Durchführung des BundesImmissionsschutzgesetzes (Verordnung über kleine und mittlere Feuerungsanlagen - 1. BImSchV): 1. BImSchV

6. Win KM, Persson T, Bales C (2012) Particles and gaseous emissions from realistic operation of residential wood pellet heating systems. Atmos Environ 59:320-327. https://doi.org/10.1016/j. atmosenv.2012.05.016

7. Schmidl C, Luisser M, Padouvas E, Lasselsberger L, Rzaca M, Ramirez-Santa Cruz C, Handler M, Peng G, Bauer H, Puxbaum $\mathrm{H}$ (2011) Particulate and gaseous emissions from manually and automatically fired small scale combustion systems. Atmos Environ 45(39):7443-7454. https://doi.org/10.1016/j.atmosenv. 2011.05.006

8. Fatehi H, Li ZS, Bai XS, Aldén M (2017) Modeling of alkali metal release during biomass pyrolysis. Proc Combust Inst 36(2):22432251. https://doi.org/10.1016/j.proci.2016.06.079

9. Jokiniemi JK, Lazaridis M, Lehtinen KEJ, Kauppinen EI (1994) Numerical simulation of vapour-aerosol dynamics in combustion processes. J Aerosol Sci 25(3):429-446

10. Lind T, Kauppinen EI, Hokkinen J, Jokiniemi JK, Orjala M, Aurela M, Hillamo R (2006) Effect of chlorine and sulfur on fine particle formation in pilot-scale CFBC of biomass. Energy Fuel 20(1):6168. https://doi.org/10.1021/ef050122i

11. Fagerström J, Steinvall E, Boström D, Boman C (2016) Alkali transformation during single pellet combustion of soft wood and wheat straw. Fuel Process Technol 143:204-212. https://doi.org/ 10.1016/j.fuproc.2015.11.016

12. Sippula O, Lind T, Jokiniemi J (2008) Effects of chlorine and sulphur on particle formation in wood combustion performed in a laboratory scale reactor. Fuel 87(12):2425-2436. https://doi.org/ 10.1016/j.fuel.2008.02.004

13. Olave RJ, Forbes EGA, Johnston CR, Relf J (2017) Particulate and gaseous emissions from different wood fuels during combustion in a small-scale biomass heating system. Atmos Environ 157:49-58. https://doi.org/10.1016/j.atmosenv.2017.03.003

14. Sommersacher P, Brunner T, Obernberger I (2012) Fuel indexes: a novel method for the evaluation of relevant combustion properties of new biomass fuels. Energy Fuel 26(1):380-390. https://doi.org/ 10.1021/ef201282y

15. Sippula O, Hytönen K, Tissari J, Raunemaa T, Jokiniemi J (2007) Effect of wood fuel on the emissions from a top-feed pellet stove. Energy Fuel 21(2):1151-1160. https://doi.org/10.1021/ef060286e

16. Lamberg H, Tissari J, Jokiniemi J, Sippula O (2013) Fine particle and gaseous emissions from a small-scale boiler fueled by pellets of various raw materials. Energy Fuel 27(11):7044-7053. https://doi. org/10.1021/ef401267t

17. Tran K-Q, Iisa K, Steenari B-M, Lindqvist O (2005) A kinetic study of gaseous alkali capture by kaolin in the fixed bed reactor equipped with an alkali detector. Fuel 84(2-3):169-175. https://doi.org/10. 1016/j.fuel.2004.08.019

18. Sommersacher P, Brunner T, Obernberger I, Kienzl N, Kanzian W (2013) Application of novel and advanced fuel characterization tools for the combustion related characterization of different wood/kaolin and straw/kaolin mixtures. Energy Fuel 27(9):5192_5206. https://doi.org/10.1021/ef400400n

19. Bäfver LS, Rönnbäck M, Leckner B, Claesson F, Tullin C (2009) Particle emission from combustion of oat grain and its potential reduction by addition of limestone or kaolin. Fuel Process Technol 90(3):353-359. https://doi.org/10.1016/j.fuproc.2008.10. 006

20. Carroll JP, Finnan JM (2015) The use of additives and fuel blending to reduce emissions from the combustion of agricultural fuels in small scale boilers. Biosyst Eng 129:127-133. https://oi.org/10. 1016/j.biosystemseng.2014.10.001

21. Gehrig M, Wöhler M, Pelz S, Steinbrink J, Thorwarth H (2019) Kaolin as additive in wood pellet combustion with several mixtures of spruce and short-rotation-coppice willow and its influence on emissions and ashes. Fuel 235:610-616. https://doi.org/10.1016/j. fuel.2018.08.028

22. Gollmer C, Höfer I, Harms D, Kaltschmitt M (2019) Potential additives for small-scale wood chip combustion - laboratory-scale estimation of the possible inorganic particulate matter reduction potential. Fuel 254:115695. https://doi.org/10.1016/j.fuel.2019. 115695

23. Gehrig M, Pelz S, Jaeger D, Hofmeister G, Groll A, Thorwarth H, Haslinger W (2015) Implementation of a firebed cooling device and its influence on emissions and combustion parameters at a residential wood pellet boiler. Appl Energy 159:310-316. https://doi.org/ 10.1016/j.apenergy.2015.08.133

24. Pollex A, Zeng T, Khalsa J, Erler U, Schmersahl R, Schön C, Kuptz D, Lenz V, Nelles M (2018) Content of potassium and other aerosol forming elements in commercially available wood pellet batches. Fuel 232:384-394. https://doi.org/10.1016/j.fuel.2018.06.001

25. Jiao J, Zheng Y (2007) A multi-region model for determining the cyclone efficiency. Sep Purif Technol 53(3):266-273

26. Strassl M, Edelbauer J, Tischler F (2018) Hackschnitzel und Pelletfeuerung von $20 \mathrm{~kW}$ bis $80 \mathrm{~kW}$ mit integrierbarem Elektroabscheider. In: Thomas Nussbaumer (ed) 15. HolzenergieSymposium: Netzintegration, Vorschriften und Feuerungstechnik, pp 111-122

27. Huang S-H, Chen C-C (2002) Ultrafine aerosol penetration through electrostatic precipitators. Environ Sci Technol 36(21):4625-4632. https://doi.org/10.1021/es011157

28. Li Y, Suriyawong A, Daukoru M, Zhuang Y, Biswas P (2009) Measurement and capture of fine and ultrafine particles from a pilot-scale pulverized coal combustor with an electrostatic precipitator. J Air Waste Manage Assoc 59(5):553-559. https://doi.org/10. 3155/1047-3289.59.5.553

29. Jaworek A, Krupa A, Czech T (2007) Modern electrostatic devices and methods for exhaust gas cleaning: a brief review. J Electrost 65(3):133-155. https://doi.org/10.1016/j.elstat.2006.07.012

30. Dittler A (2001) Gasreinigung mit starren Oberflächenfiltern Erscheinungsformen und Auswirkungen unvollständiger Filterregenerierung. Dissertation, Universität Fridericiana zu Karlsruhe

31. Hartmann H, Roßmann P, Turowski P et al. (2007) Getreidekörner als Brennstoff für Kleinfeuerungen: Technische Möglichkeiten und Umwelteffekte. Berichte aus dem TFZ, Straubing

32. Schwabl M, Scheibler M, Schmidl C (2012) Endbericht GoKRT: Experimentelle Entwicklung eines Metallgewebefilters 
33. Schiller S, Schmid H-J (2015) Highly efficient filtration of ultrafine dust in baghouse filters using precoat materials. Powder Technol 279:96-105. https://doi.org/10.1016/j.powtec.2015.03.048

34. Struschka M, Goy J (2015) Entwicklung eines kompakten und kostengünstigen Gewebefilters für Biomassekessel. Institut für Feuerungs- und Kraftwerkstechnik (IFK), Universität Stuttgart

35. Yusof NSM, Babgi B, Alghamdi Y, Aksu M, Madhavan J, Ashokkumar M (2016) Physical and chemical effects of acoustic cavitation in selected ultrasonic cleaning applications. Ultrason Sonochem 29:568-576. https://doi.org/10.1016/j.ultsonch.2015. 06.013

36. Chahine GL, Kapahi A, Choi J-K, Hsiao CT (2016) Modeling of surface cleaning by cavitation bubble dynamics and collapse. Ultrason Sonochem 29:528-549. https://doi.org/10.1016/j. ultsonch.2015.04.026

37. Lanzerstorfer C (2015) Chemical composition and physical properties of filter fly ashes from eight grate-fired biomass combustion plants. J Environ Sci (China) 30:191-197. https://doi.org/10.1016/j. jes.2014.08.021

38. Tejada J, Grammer P, Kappler A, Thorwarth H (2019) Trace element concentrations in firewood and corresponding stove ashes. Energy Fuel 33(3):2236-2247. https://doi.org/10.1021/acs. energyfuels. $8 \mathrm{~b} 03732$

39. Jaworek A, Czech T, Sobczyk AT, Krupa A (2013) Properties of biomass vs. coal fly ashes deposited in electrostatic precipitator. J Electrost 71(2):165-175. https://doi.org/10.1016/j.elstat.2013.01. 009
40. DIN EN 14778:2011, Feste Biobrennstoffe - Probenahme

41. DIN EN 14780:2011, Feste Biobrennstoffe - Probenherstellung

42. DIN EN ISO 18122:2016-03, Biogene Festbrennstoffe_Bestimmung des Aschegehaltes (ISO_18122:2015); Deutsche Fassung EN_ISO_18122:2015

43. DIN EN ISO 18134-2:2017-05, Biogene Festbrennstoffe Bestimmung des Wassergehaltes - Ofentrocknung - Teil $\overline{2}$ : Gesamtgehalt an Wasser_- Vereinfachtes Verfahren (ISO_181342:2017); Deutsche Fassung EN_ISO_18134-2:2017

44. DIN EN ISO 16994:2016-12, Biogene Festbrennstoffe Bestimmung des Gesamtgehaltes an Schwefel und Chlor (ISO_16994:2016); Deutsche Fassung EN_ISO_16994:2016

45. European Pellet Council ENplus Handbook, Version 3.0, 2015: Part 3: Pellet Quality

46. DIN SPEC 33999:2014-12, Emissionsminderung_- Kleine und mittlere Feuerungsanlagen (gemäß_1. BImSchV)_- Prüfverfahren zur Ermittlung der Wirksamkeit von nachgeschalteten Staubminderungseinrichtungen

47. VDI 2066 Blatt 1:2006: Messen von Partikeln - Staubmessungen in strömenden Gasen - Gravimetrische Bestimmung der Staubbeladung

Publisher's Note Springer Nature remains neutral with regard to jurisdictional claims in published maps and institutional affiliations. 